\title{
To what extent does a pharmacy curriculum foster diversity and inclusion through paper-based case scenarios?
}

\author{
Lisa J. Kremer ${ }^{1}$, Angela Lan Anh Nguyen ${ }^{1}$ (D) , Te Awanui Waaka1 ${ }^{1}$ Jaime Tutbury ${ }^{1}$ (D) , Kyle J. Wilby² (iD, \\ Alesha Smith1 1 (iD) \\ 1 He Rau Kawakawa (School of Pharmacy), University of Otago, Dunedin, New Zealand \\ 2 College of Pharmacy, Faculty of Health, Dalhousie University, Halifax, Nova Scotia, Canada
}

\section{Keywords}

Diversity

Health equity

Higher education

Inclusion

Pharmacy education

\section{Correspondence}

Lisa Kremer

He Rau Kawakawa

(School of Pharmacy)

University of Otago

18 Frederick Street

Dunedin

New Zealand

Lisa.kremer@otago.ac.nz

\begin{abstract}
Background: There is increasing awareness of diversity and inclusion needs within health and education systems to help address access and equity issues for minority groups. Although these calls are well known, there is little guidance for those working within these systems to create meaningful change. The purpose of this study was to critically review case-based teaching material within the authors' programmes through the lens of equity, diversity, and inclusion. Methods: A document analysis of clinical workshop cases extracted from all integrated therapeutics courses administered in $\mathbf{2 0 2 0}$ was conducted. Results: Sex, age, and employment status were most commonly presented in cases $(84.0 \%, 97.1 \%, 49.0 \%$ respectively). The majority $(90.0 \%)$ of cases did not have ethnicity defined. The overwhelming majority of cases did not have living situation (68.3\%) or sexual orientation (78.0\%) defined.

Conclusion: Case-based teaching material within a pharmacy programme was largely undefined according to patient demographics and diversity markers. Findings support the notion that teaching material may have a contributory role towards systemic racism, prejudice, and implicit bias.
\end{abstract}

\section{Introduction}

There are increasing calls for diversity and inclusion responses within health and education systems (Arya et al., 2020; Accreditation Council for Pharmacy Education, 2021). These calls are largely based on a longstanding history of systemic racism, presence of implicit biases, and examples of both intentional and unintentional discrimination present within society against minority groups (Baciu, Negussie, \& Geller, 2017; Borrell et al., 2021; Lavizzo-Mourey, Besser, \& Williams, 2021). Racial stereotyping of patients, for example, contributes to systemic racism and in turn, creates access and equity disadvantages for racial minorities. Although these effects are well known, there is little guidance for those working within these systems to create meaningful change. Strategies to date have largely focused on developing cultural awareness and effective communication strategies at the individual level within health curricula but little effort has been directed towards identifying and improving system factors to help support change (Lavallee et al., 2014).

Arya and colleagues recently published a foundational paper calling for urgent change to support the dismantling of systemic racism within the pharmacy profession (Arya et al., 2020). 11 recommendations were proposed that are aimed towards supporting professional change and while focused on systemic racism, many can be applied to improving equity, diversity, and inclusion initiatives across other minority populations (e.g. gender and sexual minorities). In particular, the need for awareness, creation of spaces for open dialogue, and sharing of lessons 
learned may be most applicable across minority groups and also relevant for consideration by educational institutions. Additionally, calls from both pharmacy and medical education support critical review of institutional policies and educational materials to ensure institutional and teaching practices are safe, equitable, and foster inclusivity (Arya et al., 2020; Lim et al., 2021).

As education of health professionals evolves, there must be an increased focus on teaching material to ensure it is free from implicit biases that train students to assume 'mainstream' unless otherwise specified. For example, a case written as, 'a 78 year old married male presents to the clinic with a productive cough', may be interpreted as a white, cis-gender, heterosexual male (e.g. aligned with mainstream 'dominant' populations). A lack of clarity provided within case material could result in dominant student populations associating case material with mainstream populations and only considering minority population health when specifically referred to. This may contribute to attachment of negative stereotypes to nonmainstream populations (Greenwald \& Banaji, 1995; Greenwald et al., 2002). Minority groups may then be disadvantaged by members of the dominant mainstream group due to two main factors: 1) minority status, 2) negative societal stereotypes (Chambers et al., 1998; Katz, Joiner, \& Kwon, 2002).

Based on the need to address systemic racism and discrimination within educational institutions and the known contributory influence of teaching materials that may facilitate negative attitudes and stereotyping, a critical review of programme materials is warranted. Although there is no known formula for the 'right' amount of diversity within teaching materials, it is the authors perspective that students should be presented with cases that reflect societal patterns. Minority populations should therefore be: 1) represented and 2) represented fairly without always or almost always assigning a specific characteristic to the case that could result in stereotyping (e.g. Human Immunodeficiency Virus for gay male cases, low socioeconomic status for Indigenous cases) (Muntinga et al., 2016). Cases should also have enough definition and clarity to avoid defaulting students to always assuming 'mainstream' unless otherwise specified.

The purpose of this study was to critically review casebased teaching material within our programme through the lens of equity, diversity, and inclusion. The specific aims were to identify to what extent diversity was represented within case materials and to determine if the diversity included adequately represented the full spectrum of minority populations.

\section{Methods \\ Study design and setting}

This was a document analysis of patient cases extracted from small group learning sessions that occurred in 2020 across the Bachelor of Pharmacy curriculum at the University of Otago in New Zealand (Bowen, 2009). The Bachelor of Pharmacy programme is a four-year degree with three professional years of study. On-campus teaching events are generally aligned through introductory didactic lectures, small-group case-based learning exercises, and practical professional skills laboratory exercises. For the purposes of this study, case material was extracted only from small-group case-based learning exercises.

New Zealand is a diverse country made up of 4.7 million people. According to the 2018 census data, the country is made up of New Zealand European (70.0\%), Māori (16.5\%), Pacific Peoples (8.0\%), Asian (15.0\%), and other ethnic groups.(Statistics, 2013a) There are over a million people living in Aotearoa New Zealand with a disability (24.0\% of the population) (Statistics, 2013b). There are roughly equal numbers of males and females, yet no official data is known for sexually and gender diverse individuals.

\section{Data collection}

Case-based learning material was extracted from all smallgroup case-based learning exercises conducted during the three professional years of study. Cases were included in the analysis if they included at least one piece of demographic or social data (i.e. age, gender or sex, height, weight, body mass index, occupation, allergy status, alcohol use, smoking status, illicit drug use, exercise, diet, relationship status, living arrangement, or sexual orientation). Cases were excluded if no demographic information was provided for the person (e.g. only the medical condition and/or medications were provided). All case data were extracted into a Microsoft Excel spreadsheet.

\section{Data analysis}

Once extracted, case data was reviewed and categorised according to the following factors:

-Demographic characteristics: Age, sex, ethnicity, employment status, employment type, living situation, sexual orientation, and relationship status.

- Clinical Characteristics: Medical conditions, number of medicines prescribed, allergies, height, weight and Body Mass Index (BMI). 
-Social Characteristics: Smoking status, use of alcohol and/or illicit drugs, and frequency of exercise.

If a case did not mention a characteristic listed above, it was recorded as 'undefined'. If there was a lack of specificity about the factors, they were also recorded as undefined. Examples of these included specifying a partner but without mention of the partner's gender (sexual orientation $=$ undefined), specifying he or she was assumed to represent gender unless the case specified the patient was transgender, ethnicity was classified as the priority ethnicity (as per the Ministry of Health guideline, 2010) if multiple ethnicities given, and ethnicities for names typically associated with specific cultural groups were also classified as undefined unless ethnicity was explicitly stated. Categorisation of data was completed by one of three investigators (LK, AW, or AN) but reviewed and discussed in person by all investigators. Discrepancies in categorisation were resolved using discussion and consultation with the full investigator team.

\section{Statistical analysis}

Categorised data was summarised using descriptive statistics (proportion of all cases) across all factors identified. Data was also stratified per professional year. Medical conditions, social factors, and other relevant case data was also summarised descriptively for each minority group identified.

\section{Data analysis}

Three investigators (LK, AN, AW) met to review approximately $20 \%$ of the dataset to develop an initial coding framework specific to research questions. LK, AW and $\mathrm{AN}$ then independently coded all data according to this framework. The investigator team then met for a final review of coding. Discrepancies were resolved during an in-person review.

Descriptive analytics were undertaken using Microsoft Excel.

\section{Results}

208 cases from 62 workshops met the inclusion criteria for the document analysis.

\section{Demographic characteristics}

Ethnicity was infrequently defined with $10.0 \%$ of cases ethnicity specified (Table I). Out of 208 cases, there were five $(2.4 \%)$ and four (1.9\%) of cases where the patient was defined as Māori or Pacific Peoples, respectively. Sexual orientation (78.0\%), living situation (86.0\%), and employment status (51.0\%) were undefined in the majority of cases. Cases where employment was stated, the majority of cases had either High School of University education $(17.0 \%)$, or were working in business management or administration roles (3.3\%). Overall, there was a good variety of employment type stated in cases.

\section{Clinical characteristics}

Medical condition(s) and number of medicines were well defined variables (Table II). Hypertension, hypercholesterolemia/dysrythmias, thyroidism, type 2 diabetes, and bipolar disorder were the top five most common conditions presented. In most cases, patients were prescribed one to four medicines.

In cases with Māori patients, $80.0 \%$ had hypertension, $60.0 \%$ hypercholesterolaemia, $60.0 \%$ type 2 diabetes, and other conditions. $100 \%$ of Pacific people patients had hypertension, 75.0\% hypercholesterolaemia, 75.0\% type 2 diabetes and $50.0 \%$ had gout. These cases were all condensed into one third year course.

Case based scenarios of chronic obstructive pulmonary disease (100\%), myocardial infarction (67.0\%), and dysrhythmia $(71.0 \%)$ cases were presented in male patients. All oncology patients (except breast cancer) were either male or undefined. Type 1 diabetes mellitus (71.0\%) cases were presented in female patients. Schizophrenia cases were male $(63.0 \%)$ or undefined $(37.0 \%)$. Of cases where gender was indicated as 'other', the only medical condition presented was for gender affirming hormone therapy.

Patient height (84.6\%), weight (78.0\%), BMI (83.0\%) and allergy status $(65.0 \%)$ were undefined in the majority of cases.

\section{Social characteristics}

Overall, social characteristic information was not often presented (Table III). Smoking status was presented in $21.0 \%$ of cases, alcohol in $16.0 \%$ of cases, illicit drug use in $27.0 \%$ of cases, and exercise status in $13.0 \%$ of cases. 
Table I: Demographic characteristics

\begin{tabular}{|c|c|c|}
\hline \multicolumn{3}{|l|}{ Age } \\
\hline & Number & Percentage \\
\hline Undefined & 6 & $2.9 \%$ \\
\hline $0-20$ & 35 & $16.8 \%$ \\
\hline $21-40$ & 62 & $30.0 \%$ \\
\hline $41-60$ & 51 & $24.5 \%$ \\
\hline $61-80$ & 48 & $23.1 \%$ \\
\hline 81 & 6 & $2.9 \%$ \\
\hline \multicolumn{3}{|l|}{ Gender } \\
\hline Undefined & 34 & $16.0 \%$ \\
\hline Male & 87 & $42.0 \%$ \\
\hline Female & 85 & $41.0 \%$ \\
\hline Other & 2 & $1.0 \%$ \\
\hline \multicolumn{3}{|l|}{ Ethnicity } \\
\hline Undefined & 187 & $90 \%$ \\
\hline Māori & 5 & $2.5 \%$ \\
\hline Pacific Peoples & 4 & $1.9 \%$ \\
\hline Asian & 2 & $1.0 \%$ \\
\hline \multicolumn{3}{|l|}{ Employment status } \\
\hline Undefined & 108 & $51.0 \%$ \\
\hline Child (0-12) & 17 & $8.0 \%$ \\
\hline Student $(13+)$ & 12 & $5.7 \%$ \\
\hline Unemployed & 5 & $2.4 \%$ \\
\hline Retired & 11 & $5.2 \%$ \\
\hline Employed & 55 & $27.7 \%$ \\
\hline Total & 208 & $100 \%$ \\
\hline \multicolumn{3}{|l|}{ Employment type } \\
\hline High School/University Education & 10 & $17.0 \%$ \\
\hline Arts, Audio/Video Technology, Communications & 3 & $1.4 \%$ \\
\hline Business Management and Administration & 7 & $3.3 \%$ \\
\hline Education and Training & 4 & $1.9 \%$ \\
\hline Finance & 4 & $1.9 \%$ \\
\hline Government and Public Administration & 0 & $0.0 \%$ \\
\hline Health Science & 6 & $2.8 \%$ \\
\hline Hospitality and Tourism & 6 & $2.8 \%$ \\
\hline Human Services & 1 & $0.5 \%$ \\
\hline Information Technology & 1 & $0.5 \%$ \\
\hline Law, Public Safety, Corrections, Security & 3 & $1.4 \%$ \\
\hline Manufacturing & 1 & $0.5 \%$ \\
\hline Marketing, Sales, Service & 1 & $0.5 \%$ \\
\hline Science, Technology, Engineering, Mathematics & 4 & $1.9 \%$ \\
\hline Transportation, Distribution, Logistics & 1 & $0.5 \%$ \\
\hline Not defined & 154 & $72.6 \%$ \\
\hline Total & 212 & $100 \%$ \\
\hline \multicolumn{3}{|l|}{ Living situation } \\
\hline Available & 46 & $31.7 \%$ \\
\hline Not defined & 99 & $68.3 \%$ \\
\hline Total & 145 & $100 \%$ \\
\hline \multicolumn{3}{|l|}{ Sexual orientation } \\
\hline Available & 20 & $9.6 \%$ \\
\hline Not defined & 189 & $90.4 \%$ \\
\hline Total & 209 & $100 \%$ \\
\hline \multicolumn{3}{|l|}{ Relationship status } \\
\hline Available & 30 & $20.4 \%$ \\
\hline Not defined & 117 & $79.6 \%$ \\
\hline Total & 147 & $100 \%$ \\
\hline
\end{tabular}


Table II: Clinical characteristics

\begin{tabular}{lr}
\hline Cardiovascular & Number \\
\hline Hypertension & \% \\
Hypercholestralaemia & $8.4 \%$ \\
Dysrythmia (Atrial Fib) & $4.3 \%$ \\
Other: e.g., DVT/HF/MI/angina & 14 \\
\hline
\end{tabular}

\begin{tabular}{|c|c|c|}
\hline Respiratory & & \\
\hline Asthma & 11 & $3.4 \%$ \\
\hline COPD & 4 & $1.2 \%$ \\
\hline
\end{tabular}

Other: e.g., Pneumonia, lung disease, klebsiella pneumonia 4

\begin{tabular}{lll}
\hline Diabetes & & \\
\hline Type 1 Diabetes & $2.2 \%$ \\
Type 2 Diabetes & $4.3 \%$ & 14 \\
\hline
\end{tabular}

$\begin{array}{ll}\text { Gestational Diabetes } & 0.3 \%\end{array}$

\section{Renal}

Acute Kidney Injury

Kidney Disease

Urinary Tract Infection/pyelonephritis

\section{Thyroid}

Thyroidism 16

Graves

Addison's Disease

1

$\begin{array}{ll}1 & 1 \\ & 0.3 \%\end{array}$

\section{Cancer}

Breast

Lung

Leukaemia/Lymphoma

Other: e.g. Prostate and colorectal

$3-0.9 \%$

$30.9 \%$

$3 \quad 0.9 \%$

\begin{tabular}{lr} 
Dermatology & \\
\hline Infection e.g. Cellulitis, oral candidiasis, bacterial conjunctivitis, otitis externa, otitis media & $2.2 \%$ \\
Other: e.g. Mouth ulcer, sunburn, uticaria & $1.2 \%$ \\
Acne & $1.2 \%$ \\
Atopic Dermatitis & $4.9 \%$ \\
Gastrointestinal & 3 \\
GORD/H-pylori/Dyspepsia & $3.7 \%$ \\
Diarrhoea & $3.1 \%$ \\
Other: e.g., Constipation, IBD & 12 \\
& $3.1 \%$
\end{tabular}

\begin{tabular}{lr}
\hline Muscoloskeletal & \\
\hline Osteoarthritis & $8.5 \%$ \\
Gout & $1.6 \%$ \\
Other: e.g., Arthritis and osteoporosis & 5 \\
\hline
\end{tabular}

Mental Health

Bipolar Disorder

Schizophrenia

Other: e.g. mania, personality disorder, anxiety, insomnia, epilepsy, dementia

$2.5 \%$
$7.2 \%$

\section{Other}

$\begin{array}{lll}\text { Undefined or no medical condition } & 3.7 \%\end{array}$

\begin{tabular}{ll} 
Wounds & 10 \\
\hline
\end{tabular}

$\begin{array}{ll}\text { Hayfever } & 2.8 \%\end{array}$

Men's/Women's health, e.g. Dysmenorrhea, pregnancy and breast feeding, menopause, gender affirming hormone 8

therapy, erectile dysfunction/BPN

Infection related e.g. HIV, hepatitis, pyrexia $\quad 2.5 \%$

Other: e.g. Sciatica, glaucoma, iron deficiency/anaemia, adverse drug reaction, fracture, headache/migraine, nausea/ 13

vomiting, stroke

Total 
Table II: Clinical characteristics (continued)

\begin{tabular}{|c|c|c|}
\hline Number of Medicines & & \\
\hline Undefined & 25 & $12.0 \%$ \\
\hline 0 & 29 & $14.6 \%$ \\
\hline $1-4$ & 127 & $61.1 \%$ \\
\hline $5-9$ & 25 & $12.1 \%$ \\
\hline 10 & 2 & $1.0 \%$ \\
\hline Total & 208 & $100 \%$ \\
\hline No known allergy & 46 & $21.8 \%$ \\
\hline Medicine or food allergy & 23 & $10.9 \%$ \\
\hline Other allergy & 4 & $1.9 \%$ \\
\hline Not defined & 138 & $65.4 \%$ \\
\hline Total & 211 & $100 \%$ \\
\hline \multicolumn{3}{|l|}{ Height } \\
\hline Not defined & 176 & $84.6 \%$ \\
\hline Total & 208 & $100 \%$ \\
\hline \multicolumn{3}{|l|}{ Weight } \\
\hline Available & 46 & $22 \%$ \\
\hline Not defined & 162 & $78 \%$ \\
\hline Total & 208 & $100 \%$ \\
\hline \multicolumn{3}{|l|}{ Body Mass Index } \\
\hline Available & 36 & $17 \%$ \\
\hline Not defined & 172 & $83 \%$ \\
\hline Total & 208 & $100 \%$ \\
\hline
\end{tabular}

Table III: Social characteristics

\begin{tabular}{lll}
\hline Smoking & Number & $\%$ \\
\hline Undefined & 163 & $79.1 \%$ \\
Smoker & 16 & $7.8 \%$ \\
Used to smoke & 8 & $3.9 \%$ \\
Non-smoker (Never) & 19 & $9.2 \%$ \\
Total & $\mathbf{2 0 6}$ & $\mathbf{1 0 0 \%}$ \\
& & \\
\hline Alcohol & & \\
\hline Undefined & 174 & $83.7 \%$ \\
Drinks regularly & 19 & $9.1 \%$ \\
Drinks occasionally & 7 & $3.4 \%$ \\
Does not drink & 8 & $3.8 \%$ \\
Total & $\mathbf{2 0 8}$ & $\mathbf{1 0 0 \%}$ \\
& & \\
\hline Use of Illicit Drugs & & \\
\hline Yes & 74 & $27.0 \%$ \\
No & 205 & $73.0 \%$ \\
Total & $\mathbf{2 7 9}$ & $\mathbf{1 0 0 \%}$ \\
& & \\
\hline Exercise & & \\
\hline Undefined & 182 & $87.1 \%$ \\
Regularly & 18 & $8.6 \%$ \\
Occasionally & 2 & $1.0 \%$ \\
None & 7 & $3.3 \%$ \\
Total & $\mathbf{2 0 9}$ \\
\hline & & \\
\hline
\end{tabular}

\section{Discussion}

This study critically reviewed case-based teaching material within the authors programme through the lens of equity, diversity, and inclusion. Results of this study indicate that diversity was not prevalent within case materials, indicating minority populations were not well represented. Gender, age, and employment status, and employment type were well presented in case material, however the majority of cases did not have ethnicity defined, and the overwhelming majority of cases did not have living situation or sexual orientation defined. Results from this study demonstrate that while teaching materials may not be directly contributing to stereotypes of minority groups, they may be indirectly contributing by not providing enough detail to allow students to visualise patients outside of their own cognitive norms and groupings (Liberman, Woodward, \& Kinzler, 2017).

Racism and implicit bias have a complex and multi-faceted effect that has an influence on health outcomes and inequities. Cormack and authors describe racial/ethnic bias amongst individual health providers as 'a manifestation of a broader context of pervasive exposure 
to racism and racialised discourses at a societal level', therefore health educators could be unintentionally contributing to this, with repetition of mainstream stereotypes (Cormack et al., 2018). The lack of detail within the case materials could unintentionally cause students to make assumptions about the case, based on their exposure to racism and other prejudices within society, which could be largely influenced by mainstream values. For medical institutions to continue to play the important role of eliminating health inequities, action must be taken to ensure diversity and inclusion is represented and free from bias within the case materials (Jones et al., 2019). Emphasis on this should be just as great as teaching clinical knowledge.

In contrast to demographic detail, medical conditions and medications were almost always well described. Hypertension, hypercholesterolemia, thyroid disorders, type 2 diabetes, and bipolar disorder were the top five most common conditions presented. And in most cases, patients were prescribed one to four medicines. Results also show that these most common conditions were not equitably spread across a diverse population, demonstrated by Pacific Peoples cases consistently having high blood pressure, hypercholesterolaemia, diabetes, and gout. Moving forward, educators must be aware of the conditions assigned to case patients from minority populations to ensure that stereotypes are not reinforced. With respect to Pacific Peoples described above, the inclusion of all cases having a primary or secondary condition of hypertension may prompt students to develop stereotypes by continued reinforcement of characteristics presented for a given population (Wild et al., 2021).

Social characteristics were also poorly defined in the majority of cases. If educators omit information on smoking status, illicit drug use, and alcohol use to students, this results in these groups not being visible, and therefore the health benefit of addressing social influences of health may be lost. In order to ensure students develop a process to think holistically about patients, rather than simply narrow in on a therapeutic problem, representation of this information could be valuable to describe more frequently throughout case descriptions.

To address the omitted demographic, clinical, and social characteristic information and therefore the potential for assumptions to be made by the student, there is an argument for providing cases or 'models' that encompass a full spectrum of minority populations is a concept supported by social cognition theory (Liberman et al., 2017). Social cognition theory states that individuals use categorisation to cope with large amounts of, and the complexity of, information presented to them. For example, if a student continually receives cases that associate a specific population with a condition or characteristics (e.g. Pacific Peoples and hypertension), students may ultimately categorise all Pacific Peoples in this way as they encounter patients and complexity in practice. Doing so could divert their attention away from other ailments or screening needs by shifting their focus towards a characteristic inappropriately deemed to be a 'population norm'. The same may hold true for demographics aside from ethnicity, including sexual health needs for sexually diverse individuals, as well as assumptions of health literacy for those with disabilities or language barriers. Working towards creating cases that accurately and fairly reflect diversity within society should therefore be a priority moving forward.

Findings of this study call for practical implications aside from a more conscious approach to case creation. Ongoing and sustained professional development for all staff is required to ensuring the curriculum is diverse and inclusive, because claiming to be 'fully' culturally competent or culturally safe is likely not achievable. Professional development activities can be aligned with those called for by Arya and colleagues and designed to stimulate greater reflection and awareness of systemic racism, prejudice, and implicit bias within health and education systems. Approaches of diversity teaching to students may also need to be reviewed. Educators are quick to focus on population-level facts and statistics (that largely inform case development) but training must include discussions about diversity, assumptions made about populations, and the need to provide personcentred care that takes into account each individual's own health status and priorities. Findings of this study also support a recommendation for programmes to regularly review teaching material through the lens of diversity and to create action plans as potential issues are identified. In response to the findings of this study and the recommendations by Arya and colleagues, the authors action points moving forward include:

1.Share findings of this analysis with faculty and staff by facilitating forums of open dialogue and discussion

2.Blueprint teaching materials to better reflect society and population diversity

3.Preform regular reviews of teaching materials to ensure minority populations are represented fairly and fully

Findings of this study support future research initiatives. The impact of providing undefined cases to students 
should be explored. For example, if a case does not specify ethnicity, sexuality, or gender identity, how do students visualise the case patient when moving through therapeutic exercises. Do students simply assume mainstream characteristics? Or, do different groups of students categorise according to their own experiences and identities? Secondly, how does inclusion of distinctive characteristics modify the way students approach the case? Do students instinctively assume population-level assumptions and stereotypes? Do they come into conflict or tension if the cases are not represented according to their own cognitive categorisation? Finally, does repetitive exposure to cases representing the full spectrum of diverse populations work to change assumptions and the way that students approach these cases?

\section{Limitations}

This study has limitations that should be addressed. Cases were extracted from small group case-based learning sessions but did not include cases developed for role plays or other exercises within the professional skills laboratory or other teaching events such as lectures. As these cases were largely communication focused, they lacked the details required to meet the inclusion criteria for this study. Secondly, this study was limited to one institution's experience and therefore specific findings are not transferable across settings. The conclusions and action plans, however, provide a framework for others to undertake their own, similar research. Finally, the undefined category for ethnicity may be over-represented as some case writers may have assumed that using a specific name may represent one's ethnicity (e.g. Maori, South Asian). These could not be included as such due to the lack of applicability across all ethnicities.

\section{Conclusion}

This study found that case-based teaching material within a pharmacy programme was largely undefined according to patient demographics and diversity markers. Findings support the notion that teaching material may have a contributory role towards systemic racism, prejudice, and implicit bias known to occur within educational systems. In efforts to dismantle systemic racism, prejudice, and implicit bias within the profession, institutions should review teaching material and work towards accurately representing diverse populations free from assumptions and stereotypes.

\section{Disclaimer}

The views expressed in the submitted article are our own and not an official position of the institution.

\section{Conflict of interest declaration}

None.

\section{Funding information}

None.

\section{Contributor statement}

LK, KW, AS, JT conceived and designed the study. LK, AN, TAW collected the data. AN, LK, AS, TAW analysed and interpreted the data. All authors contributed to drafting the manuscript. KW, AS, LK, JT revised the manuscript critically for important intellectual content. All authors approved the final version of the manuscript for publication.

\section{References}

ASHP (Accreditation Council for Pharmacy Education). (2021). PharmD Program Accreditation. Available from: https://www.acpe-accredit.org/ pharmd-program-accreditation/

Arya, V., Butler, L., Leal, S., Maine, L., Alvarez, N., Jackson, N., \& Varkey, A C. (2020). Systemic Racism: Pharmacists' Role and Responsibility. American Journal of Pharmaceutical Education, 84(11), 8418. https:// doi.org/10.5688/ajpe8418

Baciu, A., Negussie, Y., \& Geller, A. (2017). Committee on CommunityBased Solutions to Promote Health Equity in the United States; Communities in Action: Pathways to Health Equity. Washington (DC), United States of America: National Academies Press (US) Available from: https://www.ncbi.nlm.nih.gov/books/NBK425844/.

Borrell, L.N., Elhawary, J.R., Fuentes-Afflick, E., Witonsky, J., Bhakta, N., Wu, A.H.B., Bibbins-Domingo, K., Rodriguez-Santana, J., Lenior, Mą., Gavin, J.R., Kittles, R.A., Zaitlen, N.A., Wilkes, D.S., Powe, N.R., Ziv, E., \& Burchard, E.G. (2021). Race and Genetic Ancestry in Medicine - A Time for Reckoning with Racism. New England Journal of Medicine, 384(5), 474-480. https://doi.org/10.1056/NEJMms2029562

Bowen, G. (2009). Document Analysis as a Qualitative Research Method. Qualitative Research Journal, 9, 27-40. https://doi.org/10.3316/ QRJ0902027

Chambers, J.W., Kambon, K., Birdsong, B.D., Brown, J., Dixon, P., \& RobbinsBrinson, L. (1998). Africentric Cultural Identity and the Stress Experience of 
African American College Students. Journal of Black Psychology, 24(3), 368-396. https://doi.org/10.1177/00957984980243007

Cormack, D., Harris, R., Stanley, J., Lacey, C., Jones, R., \& Curtis, E. (2018). Ethnic bias amongst medical students in Aotearoa/New Zealand: Findings from the Bias and Decision Making in Medicine (BDMM) study. PloS One, 13(8), e0201168. https://doi.org/10.1371/journal.pone.0201168

Greenwald, A.G., \& Banaji, M.R. (1995). Implicit social cognition Attitudes, self-esteem, and stereotypes. Psychological Review, 102(1), 4-27. https://doi.org/10.1037/0033-295X.102.1.4

Greenwald, A.G., Banaji, M.R., Rudman, L.A., Farnham, S.D., Nosek, B.A., \& Mellott, D.S. (2002). A unified theory of implicit attitudes, stereotypes, self-esteem, and self-concept. Psychological Review, 109(1), 3-25. https:// doi.org/10.1037/0033-295X.109.1.3

Jones, R., Crowshoe, L., Reid, P., Calam, B., Curtis, E., Green, M., Hurra, T., Jacklin, K., Kamaka, M., Lacey, C., Milroy, J., Paul, D., Pitama, S., Walker, L., Webb, G., \& Ewen, S. (2019). Educating for Indigenous Health Equity: An International Consensus Statement. Academic Medicine, 94(4), 512-519. https://doi.org/10.1097/acm.0000000000002476

Katz, J., Joiner, T.E., \& Kwon, P. (2002). Membership in a Devalued Social Group and Emotional Well-Being: Developing a Model of Personal SelfEsteem, Collective Self-Esteem, and Group Socialization. Sex Roles, 47(9), 419-431. https://doi.org/10.1023/A:1021644225878

Lavallee, B., Diffey, L., Dignan, T., \& Tomascik, P. (2014). Is cultural safety enough? Confronting racism to address inequities in Indigneous health.

Lavizzo-Mourey, R.J., Besser, R.E., \& Williams, D.R. (2021). Understanding and Mitigating Health Inequities - Past, Current, and Future Directions. New England Journal of Medicine, 384(18), 1681-1684. https://doi.org/ 10.1056/NEJMp2008628

Liberman, Z., Woodward, A.L., \& Kinzler, K.D. (2017). The Origins of Social Categorization. Trends in Cognitive Sciences, 21(7), 556-568. https:// doi.org/10.1016/j.tics.2017.04.004

Lim, G.H.T., Sibanda, Z., Erhabor, J., Bandyopadhyay, S., Neurology, \& Neurosurgery Interest, G. (2021). Students' perceptions on race in medical education and healthcare. Perspectives on medical education, 10(2), 130-134. https://doi.org/10.1007/s40037-020-00645-6

Muntinga, M.E., Krajenbrink, V.Q., Peerdeman, S.M., Croiset, G., \& Verdonk, P. (2016). Toward diversity-responsive medical education: taking an intersectionality-based approach to a curriculum evaluation. Advances in Health Science Education Theory Practice, 21(3), 541-559. https:// doi.org/10.1007/s10459-015-9650-9

Statistics, N.Z. (2013a). 2018 Census Place Summaries. Available from: https://www.stats.govt.nz/tools/2018-census-place-summaries/newzealand

Statistics, N.Z. (2013b). Disability Survey. Available from: https:// www.stats.govt.nz/information-releases/disability-survey-2013

Wild, C.E., Rawiri, N.T., Willing, E.J., Hofman, P.L., \& Anderson, Y.C. (2021). What affects programme engagement for Māori families? A qualitative study of a family-based, multidisciplinary healthy lifestyle programme for children and adolescents. Journal of Paediatrics and Child Health, 57(5), 670-676. https://doi.org/10.1111/jpc.15309

\section{Appendix}

\section{Short Case Based Scenario \\ Peter Radley}

Peter is a 66-year-old who was diagnosed with paroxysmal atrial fibrillation 2 weeks ago. The last few weeks Peter has been experiencing cold hands and feet, and having vivid nightmares, both of which are new for him.

\section{Current medications \\ -Cilazapril $2.5 \mathrm{mg}$ PO daily \\ -Amlodipine $10 \mathrm{mg}$ PO daily \\ -Metoprolol CR 95 mg PO daily \\ Allergy status: NKDA}

\section{Long Case Based Scenario}

Mr Chin

About one year after his diagnosis of angina, Mr. Chin is bought to the Dunedin Hospital ED by ambulance with chest pain.

The pain developed suddenly whilst he was at the Botanical Gardens with his son Eric and his grandchildren. He used two doses of his GTN spray, 5 minutes apart but this gave no relief (usually would settle the pain quite quickly). He also felt short of breath and was sweating profusely. Eric called for an ambulance, which arrived within 30 minutes.

\section{Current medications}

- GTN Spray, 400mcg/puff: 1 puff SL prn

-Aspirin 100mg EC, mane

-Atorvastatin $10 \mathrm{mg}$, mane

-Cilazapril 2.5mg, mane

-Metoprolol 23.75mg, mane

Family history: Father died of a myocardial infarction at 62 years

\section{Social history}

- Current smoker, 10 cigarettes per day

-3 double whiskies ( 6 units of alcohol) daily

-5-6 cups of coffee daily (to help have energy to look after the grandchildren)

\section{Observations and laboratory results}

On admission: HR 100 beats/min BP 140/80mmHg ECG: ST elevation in V3, V4 and V5 (up to $3 \mathrm{~mm}$ )

Working diagnosis: STEMI Troponin I and Troponin T are normal

Mr. Chin is transferred for angiography $+/$ - intervention.

Findings: He had $100 \%$ occlusion of the LAD and $70 \%$ occlusion of the left circumflex. All major coronary arteries visualised had significant fatty deposits present.

Intervention: DES to both LAD and LC. No complications during the procedure. 